\title{
Analysis of Nonlinear Duopoly Game: A Cooperative Case
}

\author{
S. S. Askar, ${ }^{1,2}$ Ahmad M. Alshamrani, ${ }^{1}$ and K. Alnowibet ${ }^{1}$ \\ ${ }^{1}$ Department of Statistics and Operations Researches, College of Science, King Saud University, P.O. Box 2455, \\ Riyadh 1145, Saudi Arabia \\ ${ }^{2}$ Department of Mathematics, Faculty of Science, Mansoura University, Mansoura 35516, Egypt
}

Correspondence should be addressed to S. S. Askar; s.e.a.askar@hotmail.co.uk

Received 30 September 2014; Accepted 9 December 2014

Academic Editor: Zuo-nong Zhu

Copyright (C) 2015 S. S. Askar et al. This is an open access article distributed under the Creative Commons Attribution License, which permits unrestricted use, distribution, and reproduction in any medium, provided the original work is properly cited.

We make further attempts to investigate equilibrium stability of a nonlinear Cournot duopoly game. Our studies in this paper focus on the cooperation that may be obtained among duopolistic firms. Discrete time scales under the assumption of unknown inverse demand function and linear cost are used to build our models in the proposed games. We introduce and study here an adjustment dynamic strategy beside the so-called tit-for-tat strategy. For each model, the stability analysis of the fixed point is analyzed. Numerical simulations are carried out to show the complex behavior of the proposed models and to point out the impact of the models' parameters on the cooperation.

\section{Introduction}

There are often several duopolistic firms in economic market where competition among them is controlled by the amount of commodities they produce, the demand scheme they adopt, and the profit each firm wants to maximize. In the competition, firms produce the same or homogenous goods and they must focus not only on the market size, but also on the actions their competitors do. Game theory is one of the most important theories that is used to describe and study such competition statically and dynamically. Game theory is characterized by its ability to consider interactions among firms. The dynamic case in which the equilibrium point (Nash equilibrium) is sought and its complex dynamic characteristics are of main interest has been studied in literature [1-14].

In this paper, we argue that there is a cooperation between firms in repeated Cournot duopoly games with a generalized price function. In Cournot duopoly games, Nash equilibrium or Cournot equilibrium is the basic solution in such games and reflects the rationality of the firms within games. Since firm rationality contradicts with Pareto optimality (in cooperation case), then Nash equilibrium in duopoly game is not Pareto optimal. In other words, Pareto optimality in such games cannot be achieved by firm interest's maximization. As reported in $[15,16]$, theoretical and experimental studies have leaded up to several ways by which the cooperative solution can be obtained. For instance, in the well-known short game of prisoner's dilemma, the Nash equilibrium point is Pareto optimal as cooperation is obtainable. But for the repeated games, emergence of cooperation among competitors (firms) may be possible to achieve and then cooperation in iterated prisoner's dilemma can be explained [15, 17]. In [18], it has been shown that the conditional cooperative strategy such as the so-called "tit-for-tat" may be used to achieve cooperation among firms in repeated games.

The current paper is motivated by the work done by [15]. We introduce a duopoly game based on a generalized nonlinear inverse demand function. An adjustment dynamic strategy is introduced and studied to detect the cooperation condition that may be occurred based on this strategy. Under the proposed function, the tit-for-tat is used and a two-dimensional discrete map is introduced. The complex dynamic characteristics of this map are studied and the stability of the Nash equilibrium is investigated. The qualitative study of bifurcation is studied analytically and numerically. We conclude our study with a tit-for-tat strategy with control.

The structure of the paper is as follows: In Section 2 a description of a Cournot duopoly game based on a generalized inverse demand function is presented. In Section 3, the two-dimensional map whose iteration gives the time 
evolution based on a proposed dynamic adjustment is defined. The steady state point of the map, which is Nash equilibrium, is computed. Then the stability of this point is investigated and its complex dynamics is detected. Section 4 introduces a tit-for-tat Cournot duopoly game using the same function. As in Section 3, the dynamic characteristics of the game are investigated. In Section 5, the system studied in Section 4 is improved by adding a control strategy in this system and some discussion is illustrated. Finally, we end the paper with some conclusions to show the significance of our results.

\section{Cooperative Duopoly Model}

Suppose a market with two firms producing the same product or homogenous product. The decisions in this market are the quantities both firms sell in the market and are taken at discrete time scale, $t=0,1,2, \ldots$. The produced quantity by each firm at time $t$ is denoted by $q_{i, t}(i=1,2)$. We assume that the cost of production is linear, $C_{i, t}=c_{i} q_{i, t}$, where $c \geq 0$ is a marginal cost. Further we assume a general inverse demand function as follows:

$$
p_{t}=a-b Q_{t}^{\eta}
$$

It is well known that $p$ indicates commodity price, while $Q=\sum_{i=1}^{2} q_{i}$ is the total quantity produced by the two firms. In addition, $a$ and $b$ are positive constants and $\eta \neq-1$. The profit of each firm is now given by

$$
\pi_{i, t}=\left[a-c-b Q_{t}^{\eta}\right] q_{i, t} .
$$

In [3], the case of noncooperative duopolistic game based on incomplete information and the price function given in (1) at $\eta=3$ has been studied. In the current paper, we study the cooperation situation under the incomplete information. We assume that both firms' profits are used in the cooperative profit that is denoted by $\pi_{c}$ (cooperative profit is a maximization problem that is given by $\operatorname{Max} \pi=\pi_{1}+\pi_{2}$ ). The first-order derivative of the total profits gives the cooperative output $q_{c}=(1 / 2)[(a-c) / b(1+\eta)]^{1 / \eta}$ and then $\pi_{c}=(\eta(a-$ $c) / 2(1+\eta))[(a-c) / b(1+\eta)]^{1 / \eta}$. For the best of our knowledge, $\eta=1$ gives the work done by Ding and Shi [15].

\section{Dynamic Adjustment}

To achieve the cooperation between the two firms in the repeated game, we assume that the firms revise their beliefs by using the following dynamic adjustment:

$$
\begin{aligned}
& q_{1, t+1}=(1-v) q_{1, t}+v q_{c}, \\
& q_{2, t+1}=(1-v) q_{2, t}+v q_{c},
\end{aligned}
$$

where $v \geq 0$ is an adjusting parameter. It is assumed that the firms increase their current production in the direction $\left(q_{c}-\right.$ $\left.q_{i, t}\right)$. Now, system (3) has a unique fixed point, $e_{1}=\left(q_{c}, q_{c}\right)$. In order to study the local stability of the fixed point $e_{1}$ we need to calculate the eigenvalues of the following Jacobian:

$$
J\left(q_{c}, q_{c}\right)=\left(\begin{array}{cc}
1-v & 0 \\
0 & 1-\nu
\end{array}\right),
$$

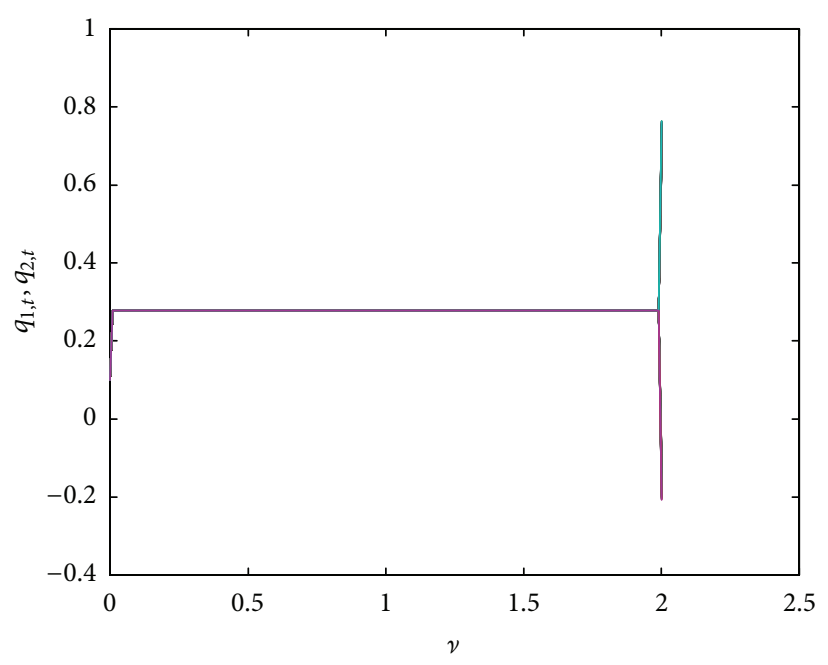

FIGURE 1: Behavior of $q_{1, t}$ and $q_{2, t}$ at the parameters: $a=3, c=2$, $b=1, \eta=1.7$, and $\nu \in(0,2)$.

which are $\lambda_{1}=\lambda_{2}=1-\nu$. Therefore, the fixed point is locally stable if $\left|\lambda_{1}\right|<1$ that gives $0<v<2$. Some numerical simulations are carried out to illustrate the complex behavior of system (3).

For system (3), we start with the values $a=3, c=2$, $b=1, \eta=1.7$. With these values, Figure 1 shows that the equilibrium point of system (3) becomes asymptotically stable under the condition $0<v<2$ and then gets unstable due to bifurcation occurred. It is observed that the parameter who has affected the stability of the equilibrium point is the adjustment parameter $\nu$. In other words, for any values of the other parameters the equilibrium point will be locally asymptotically stable at the condition $0<v<2$. On the other hand, for any values for the other parameters, say, for example, $a=3, c=2, b=1, \eta=1.7$, and a little change in $v$, say $v=2.00001$, the equilibrium point becomes unstable and chaos is obtained that is illustrated in Figure 2.

\section{Dynamic Tit-for-Tat Behavior}

Another strategy for achieving the cooperation between the two firms is the tit-for-tat strategy. With this strategy, every firm is doing what its opponent has done in the previous move. This is an incomplete information scenario; however the only things each firm knows are the output and the profit. In this situation each firm compares its profit $\pi_{i, t}$ with the cooperative profit $\pi_{c}$ that is Pareto optimal. If $\pi_{i, t}>\pi_{c}$, this means that each firm will probably reduce its output to keep the cooperation between each other. On the other hand, cooperation cannot be realized if $\pi_{i, t}<\pi_{c}$ because that indicates one of the firm is noncooperative. Based on these, map is built:

$$
q_{i, t+1}=q_{i, t}+v_{i}\left(\pi_{c}-\pi_{i, t}\right),
$$




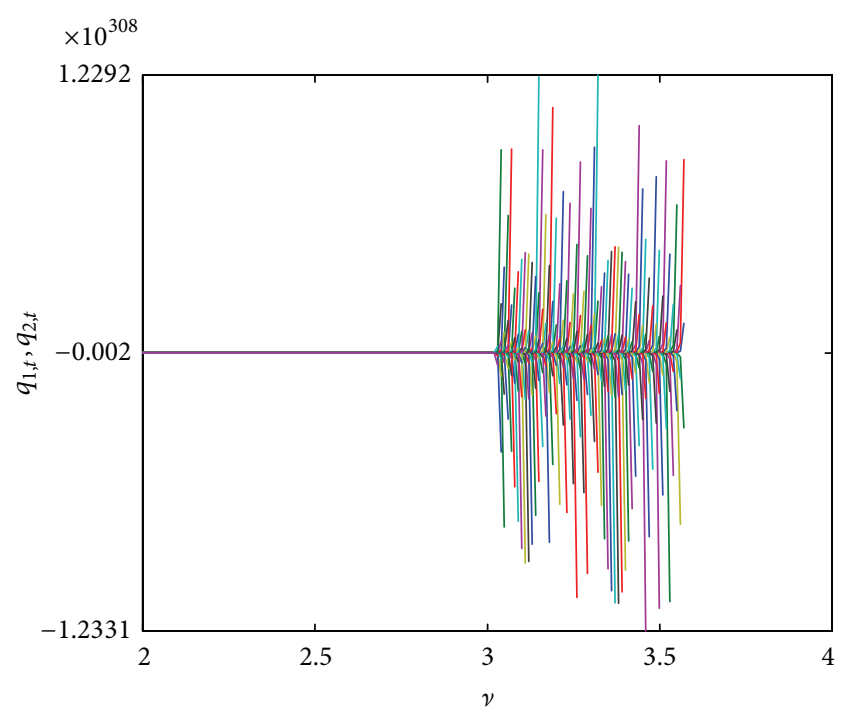

FIGURE 2: Behavior of $q_{1, t}$ and $q_{2, t}$ at the parameters: $a=3, c=2$, $b=1, \eta=1.7$, and $\nu \in[2,4]$.

where $v_{i}>0, i=1,2$, is an adjusting parameter. This map can be rewritten in the following form:

$$
\begin{aligned}
& q_{1, t+1}=q_{1, t}+v_{1}\left[\pi_{c}-\left(a-c-b Q_{t}^{\eta}\right) q_{1, t}\right], \\
& q_{2, t+1}=q_{2, t}+v_{2}\left[\pi_{c}-\left(a-c-b Q_{t}^{\eta}\right) q_{2, t}\right] .
\end{aligned}
$$

System (6) has a unique positive fixed point which is $q_{1}=$ $q_{2}=q_{c}$. The Jacobian at this point is

$$
J\left(q_{c}, q_{c}\right)=\left(\begin{array}{cc}
1-\frac{\nu_{1} \eta(a-c)}{2(1+\eta)} & \frac{\nu_{1} \eta(a-c)}{2(1+\eta)} \\
\frac{\nu_{2} \eta(a-c)}{2(1+\eta)} & 1-\frac{\nu_{2} \eta(a-c)}{2(1+\eta)}
\end{array}\right)
$$

whose eigenvalues are

$$
\begin{aligned}
& \lambda_{1}=1, \\
& \lambda_{2}=1-\frac{\nu_{1} \eta(a-c)}{2(1+\eta)}-\frac{\nu_{2} \eta(a-c)}{2(1+\eta)},
\end{aligned}
$$

where $\left|\lambda_{2}\right|<1$ if $0<\left(\nu_{1}+\nu_{2}\right)<4(1+\eta) / \eta(a-c)$ but $\lambda_{1}=1$ is a critical condition by which we cannot detect whether system (6) is stable or not. Therefore, we perform some numerical simulation to investigate the characteristics of this system. For system (6), we take $a=8, c=2, b=1, q_{0,1}=2.5$, $q_{0,2}=0.5$, and $\eta=1$. With these values, Figure 3 shows that the equilibrium point of system (6) becomes asymptotically stable. It is observed that the outputs of both firms are stable and Pareto optimality may be achieved. Figure 4 also shows that the equilibrium point is stable at the parameters $a=8$, $c=2, b=1, q_{0,1}=2.5, q_{0,2}=0.5$, and $\eta=1.3$. On the other hand, with parameters $a=8, c=2, b=1, q_{0,1}=2.5, q_{0,2}=$ 0.5 , and $\eta=0.9$. Figure 5 shows that the equilibrium point becomes unstable and Pareto optimality cannot be achieved.

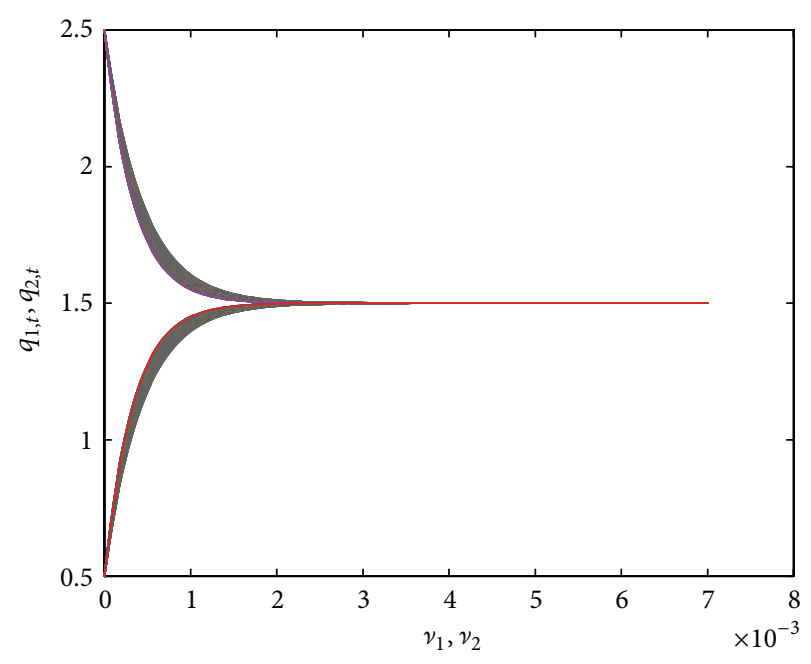

FIGURE 3: Behavior of $q_{1, t}$ and $q_{2, t}$ at the parameters: $a=8, c=2$, $b=1, q_{0,1}=2.5, q_{0,2}=0.5$, and $\eta=1$.

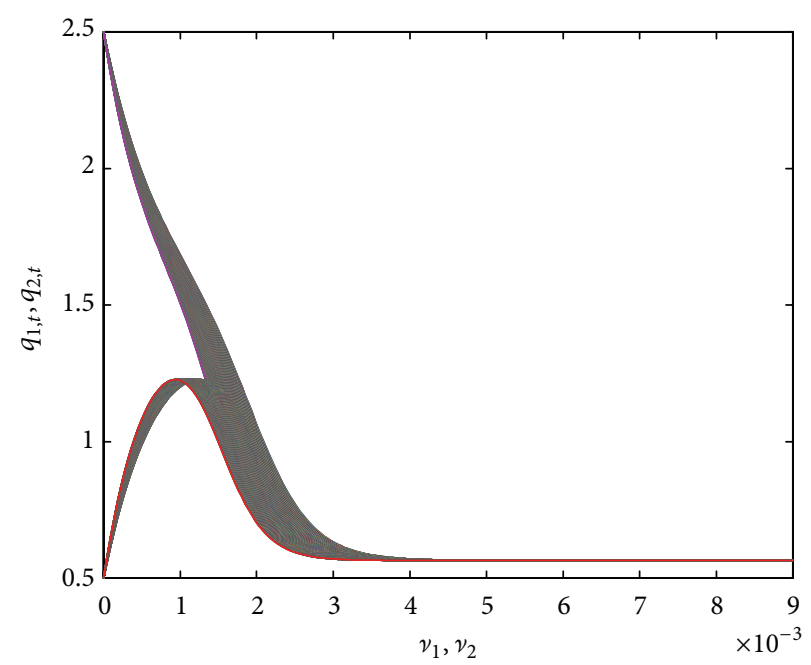

FIGURE 4: Behavior of $q_{1, t}$ and $q_{2, t}$ at the parameters: $a=8, c=2$, $b=1, q_{0,1}=2.5, q_{0,2}=0.5$, and $\eta=1.3$.

\section{Dynamic Tit-for-Tat with Control}

A feedback control is added in map (5) to improve it. This gives the following new map:

$$
q_{i, t+1}=q_{i, t}+v_{i}\left(\pi_{c}-\pi_{i, t}\right)-v\left(q_{i, t}-q_{c}\right), \quad i=1,2,
$$

where $v_{i}>0, i=1,2$, is an adjusting parameter and $v>0$ and $-\nu\left(q_{i, t}-q_{c}\right), i=1,2$, is the feedback control of the system. This feedback control shows that whether the firms cooperate or not. It is used to show that if $q_{i, t}>q_{c}(i=1,2)$, the firm is going to reduce its output in the next period of time since the current is over the cooperative output. On the other hand, if $q_{i, t}<q_{c}(i=1,2)$, the firm has to properly increase its output in the next period of time. Because of this feedback control, 


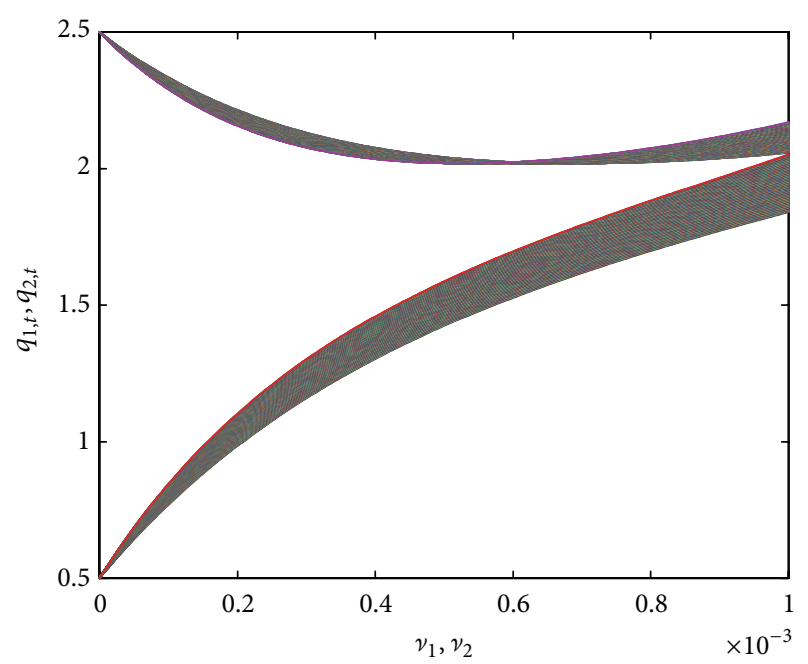

FIGURE 5: Behavior of $q_{1, t}$ and $q_{2, t}$ at the parameters: $a=8, c=2$, $b=1, q_{0,1}=2.5, q_{0,2}=0.5$, and $\eta=0.9$.

both firms have the intention to cooperate. Now, system (9) can be rewritten in the form:

$$
\begin{aligned}
& q_{1, t+1}=q_{1, t}+v_{1}\left[\pi_{c}-\left(a-c-b Q_{t}^{\eta}\right) q_{1, t}\right]-v\left(q_{1}-q_{c}\right), \\
& q_{2, t+1}=q_{2, t}+v_{2}\left[\pi_{c}-\left(a-c-b Q_{t}^{\eta}\right) q_{2, t}\right]-v\left(q_{2}-q_{c}\right) .
\end{aligned}
$$

System (10) has a unique positive fixed point which is $q_{1}=$ $q_{2}=q_{c}$. The Jacobian at this point is

$$
\begin{aligned}
& J\left(q_{c}, q_{c}\right) \\
& \quad=\left(\begin{array}{cc}
\frac{(1-v)(1+\eta)-0.5 v_{1} \eta(a-c)}{1+\eta} & \frac{0.5 v_{1} \eta(a-c)}{1+\eta} \\
\frac{0.5 v_{2} \eta(a-c)}{1+\eta} & \frac{(1-v)(1+\eta)-0.5 v_{2} \eta(a-c)}{1+\eta}
\end{array}\right)
\end{aligned}
$$

whose eigenvalues are

$$
\begin{aligned}
& \lambda_{1}=1-\nu, \\
& \lambda_{2}=\frac{(1-\nu)(1+\eta)-0.5 \eta\left(\nu_{1}+\nu_{2}\right)(a-c)}{1+\eta},
\end{aligned}
$$

where $\left|\lambda_{1}\right|<1$ if $0<\nu<2$ and $\left|\lambda_{2}\right|<1$ if $0<(\nu(1+\eta)+$ $\left.0.5 \eta\left(\nu_{1}+\nu_{2}\right)(a-c)\right) /(1+\eta)<2$ and therefore the fixed point is locally asymptotically stable. We perform some numerical simulation to investigate the characteristics of this system.

We reconsider the unstable situation $(a=8, c=2, b=1$, $q_{0,1}=2.5, q_{0,2}=0.5$, and $\left.\eta=0.9\right)$ in the previous section. Let $\nu=0.003$; the equilibrium point is asymptotically stable, as shown in Figure 6. In addition, the numerical simulation has shown that as long as $v \in(0,2)$ with the other conditions of the eigenvalues holding, the equilibrium point will be stable and the Pareto optimality holds. Figure 7 shows that Pareto optimality cannot be achieved when $v>2$.

\section{Conclusion}

In this paper we have studied the cooperation that may be obtained among duopolistic firms in the economic market.

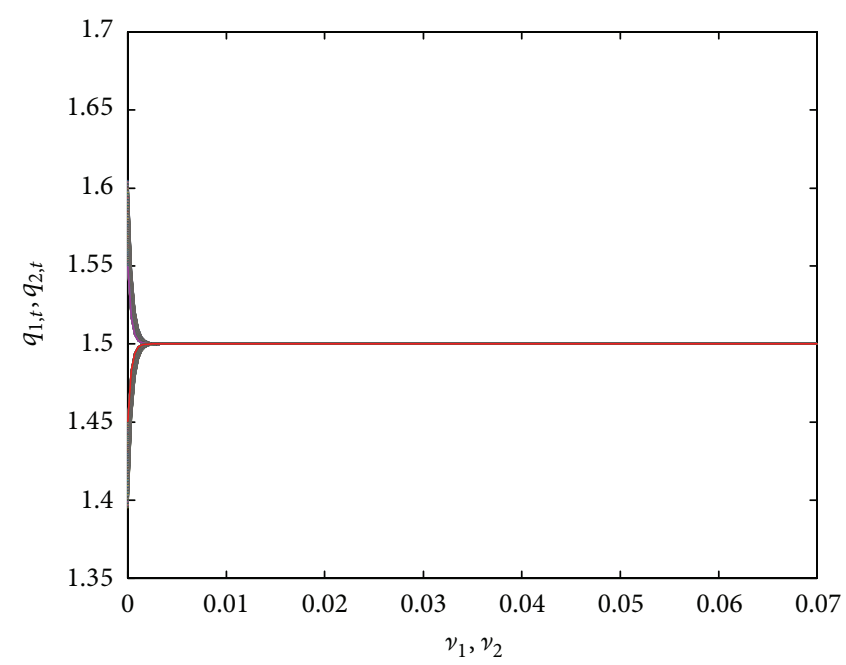

FIgURE 6: Behavior of $q_{1, t}$ and $q_{2, t}$ at the parameters: $a=8, c=2$, $b=1, q_{0,1}=2.5, q_{0,2}=0.5, v=0.003$, and $\eta=0.9$.

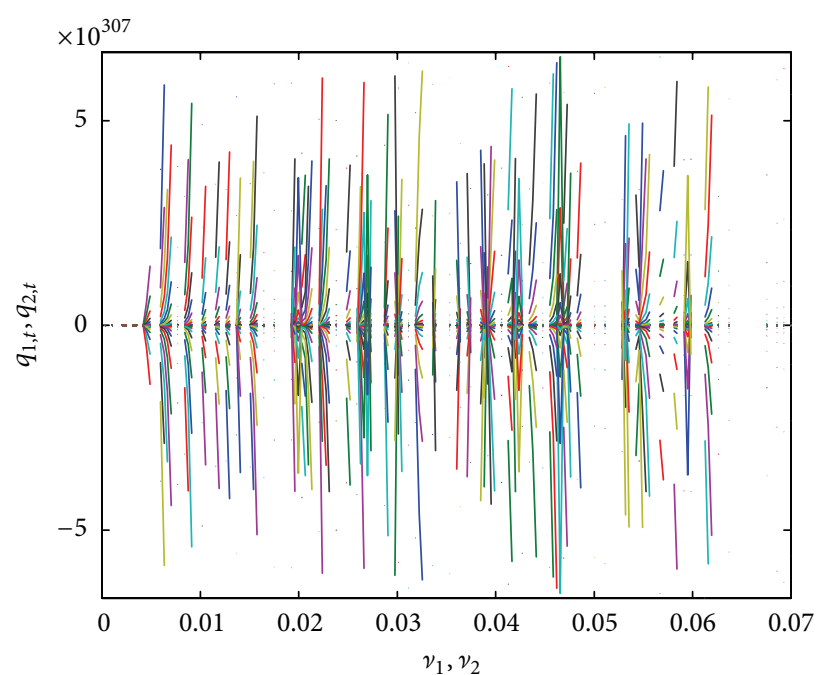

FIgURE 7: Behavior of $q_{1, t}$ and $q_{2, t}$ at the parameters: $a=8, c=2$, $b=1, q_{0,1}=2.5, q_{0,2}=0.5, v=3$, and $\eta=1$.

Based on a general nonlinear price function, three duopolistic Cournot models have been investigated. For each model, the fixed point has been computed and complete analytical and numerical studies of the stability conditions for the fixed point have been obtained. The analyses show that under the dynamic adjustment strategy and the tit-for-tat strategy, the cooperation may be achieved, but the stability in both systems is sensitive to the parameters, and the Pareto optimality cannot be assured; by improving the model-adding the feedback control to consider the cooperation intention of the firms - the firms' cooperation can be achieved, and the Pareto optimality is stable within the parameters' certain field. So the cooperation can be the result of such strategy under certain condition. 


\section{Conflict of Interests}

The authors declare that there is no conflict of interests regarding the publication of this paper.

\section{Acknowledgment}

The authors would like to extend their sincere appreciation to the Deanship of Scientific Research at King Saud University for its funding this Research group no. RG-1435-054.

\section{References}

[1] A. Cournot, Researches sur les Principes Mathematiques de la Theorie des Richesses, Hachette, Paris, France, 1838.

[2] S. S. Askar, "On complex dynamics of monopoly market," Economic Modelling, vol. 31, no. 1, pp. 586-589, 2013.

[3] S. Askar, "The rise of complex phenomena in Cournot duopoly games due to demand functions without inflection points," Communications in Nonlinear Science and Numerical Simulation, vol. 19, no. 6, pp. 1918-1925, 2014.

[4] S. S. Askar, "On Cournot-Bertrand competition with differentiated products," Annals of Operations Research, vol. 223, no. 1, pp. 81-93, 2014.

[5] S. S. Askar, "The impact of cost uncertainty on cournot duopoly game with concave demand function," Journal of Applied Mathematics, vol. 2013, Article ID 809795, 5 pages, 2013.

[6] S. S. Askar, "Complex dynamic properties of Cournot duopoly games with convex and log-concave demand function," Operations Research Letters, vol. 42, no. 1, pp. 85-90, 2014.

[7] S. S. Askar and A. Alshamrani, "The dynamics of economic games based on product differentiation," Journal of Computational and Applied Mathematics, vol. 268, pp. 135-144, 2014.

[8] S. S. Askar, "The impact of cost uncertainty on Cournot oligopoly game with concave demand function," Applied Mathematics and Computation, vol. 232, pp. 144-149, 2014.

[9] E. Ahmed, M. F. Elettreby, and A. S. Hegazi, "On quantum team games," International Journal of Theoretical Physics, vol. 45, no. 5, pp. 907-913, 2006.

[10] S. S. Asker, "On dynamical multi-team Cournot game in exploitation of a renewable resource," Chaos, Solitons \& Fractals, vol. 32, no. 1, pp. 264-268, 2007.

[11] A. K. Naimzada and L. Sbragia, "Oligopoly games with nonlinear demand and cost functions: two boundedly rational adjustment processes," Chaos, Solitons and Fractals, vol. 29, no. 3, pp. 707-722, 2006.

[12] T. Puu, "The chaotic monopolist," Chaos, Solitons and Fractals, vol. 5, no. 1, pp. 35-44, 1995.

[13] H. N. Agiza, A. S. Hegazi, and A. A. Elsadany, "The dynamics of Bowley's model with bounded rationality," Chaos, Solitons and Fractals, vol. 12, no. 9, pp. 1705-1717, 2001.

[14] H. N. Agiza and A. A. Elsadany, "Nonlinear dynamics in the Cournot duopoly game with heterogeneous players," Physica A: Statistical Mechanics and Its Applications, vol. 320, pp. 512-524, 2003.

[15] Z. Ding and G. Shi, "Cooperation in a dynamical adjustment of duopoly game with incomplete information," Chaos, Solitons and Fractals, vol. 42, no. 2, pp. 989-993, 2009.

[16] V. Cafagna and P. Coccorese, "Dynamical systems and the arising of cooperation in a Cournot duopoly," Chaos, Solitons and Fractals, vol. 25, no. 3, pp. 655-664, 2005.
[17] J.-K. Choi, “Trembles may support cooperation in a repeated prisoner's dilemma game," Journal of Economic Behavior and Organization, vol. 63, no. 3, pp. 384-393, 2007.

[18] R. Axelrod, The Evolution of Cooperation, Basic Books, New York, NY, USA, 1984. 


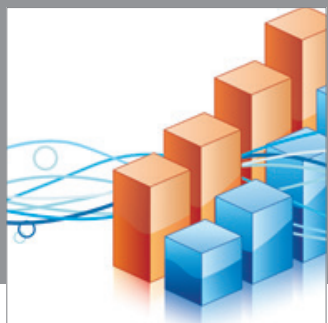

Advances in

Operations Research

mansans

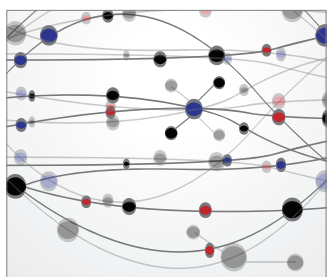

The Scientific World Journal
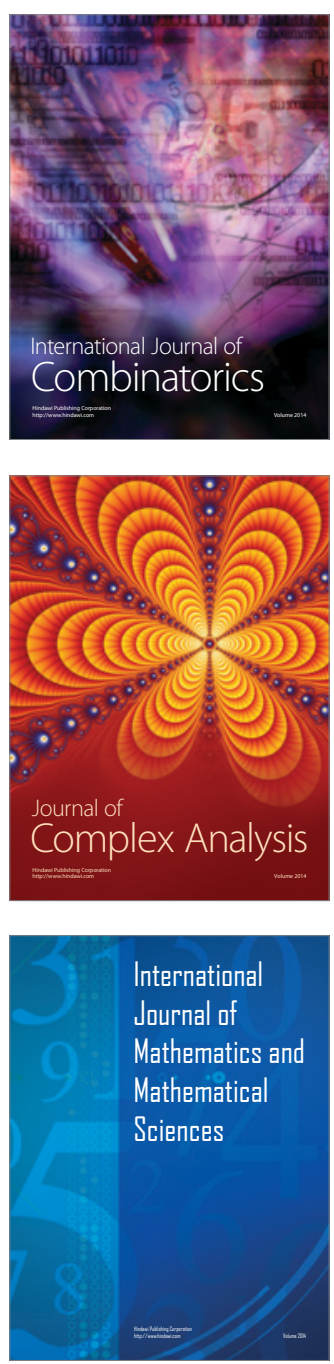
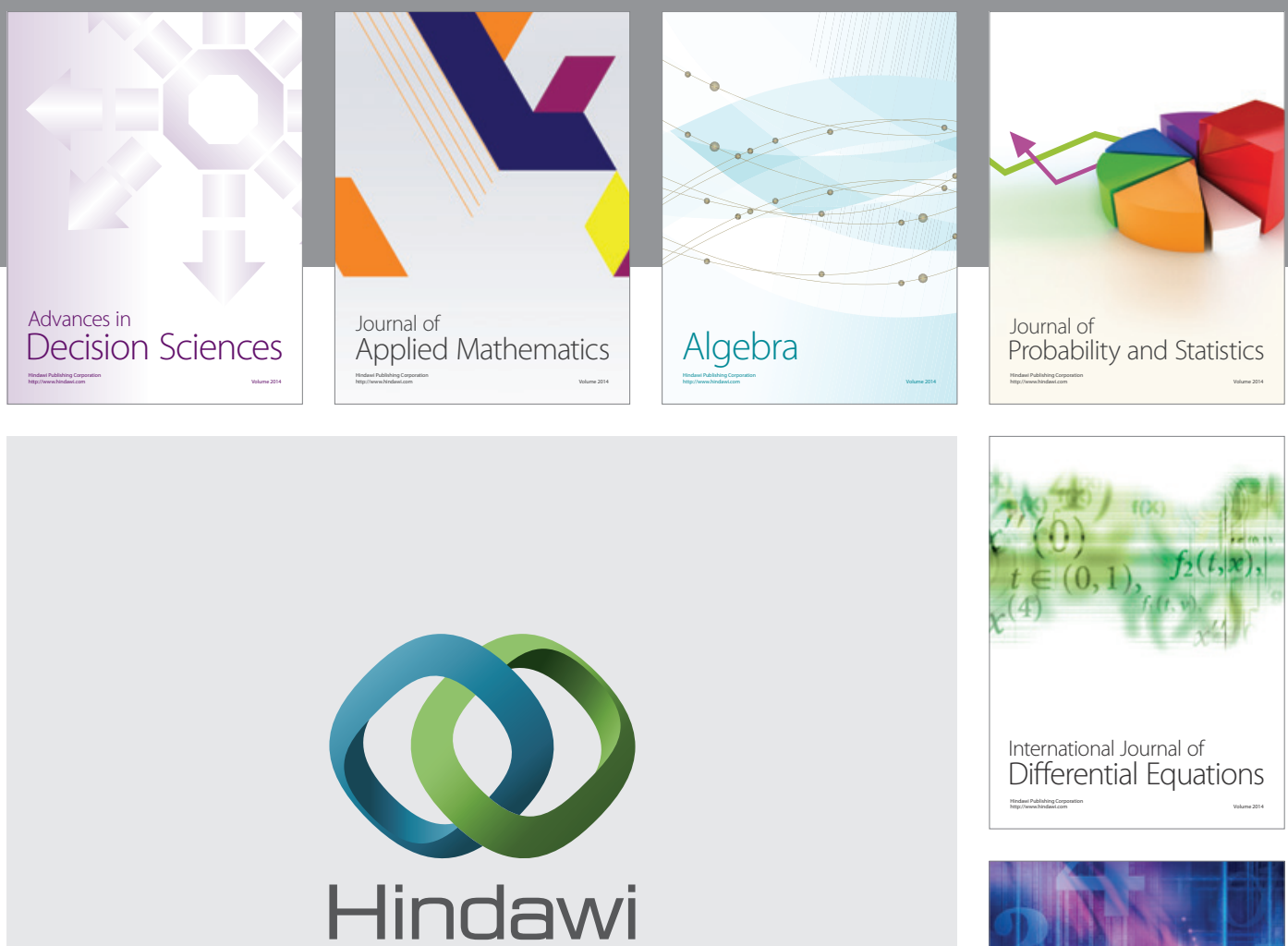

Submit your manuscripts at http://www.hindawi.com
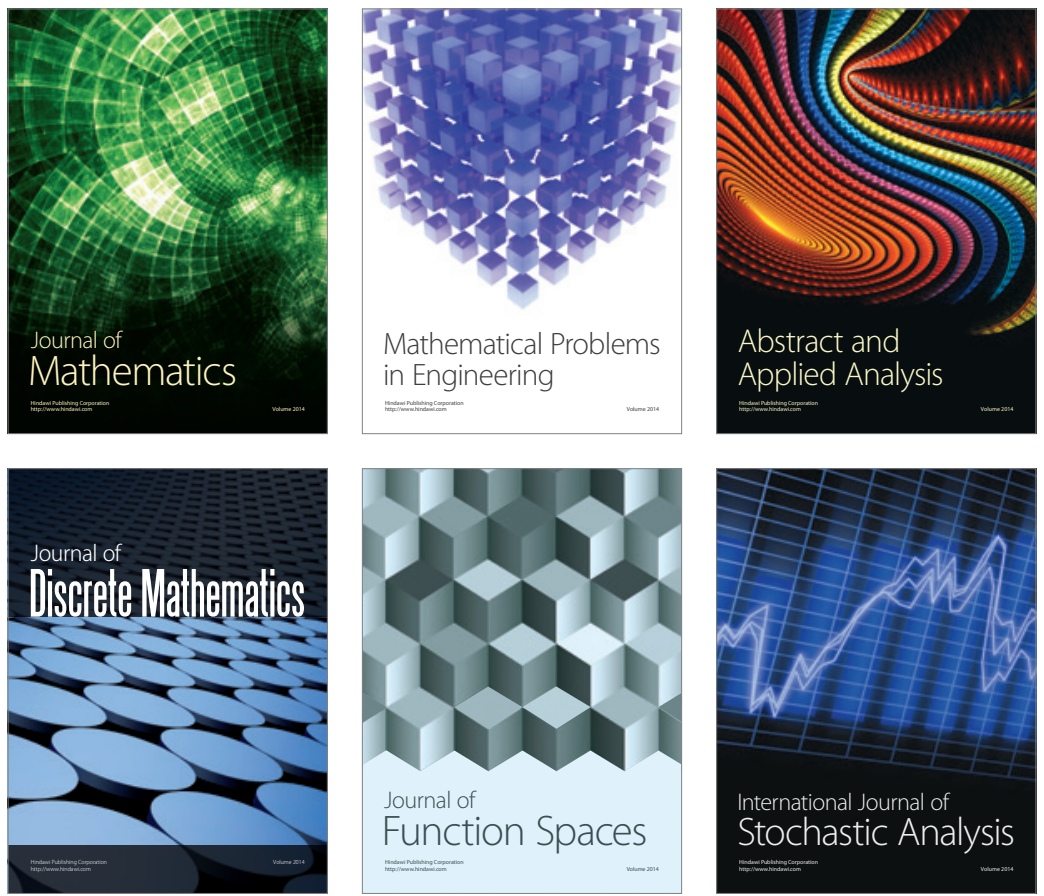

Journal of

Function Spaces

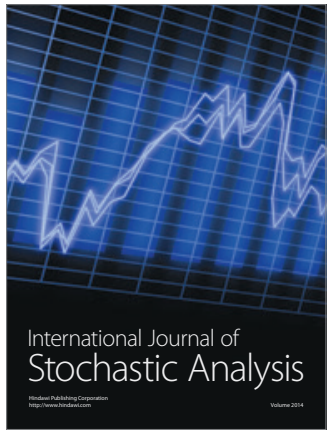

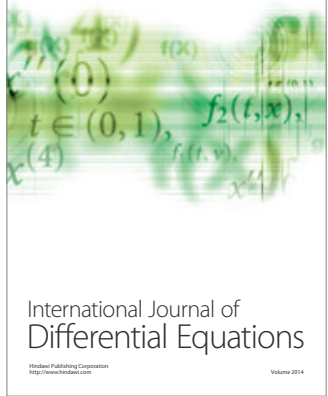
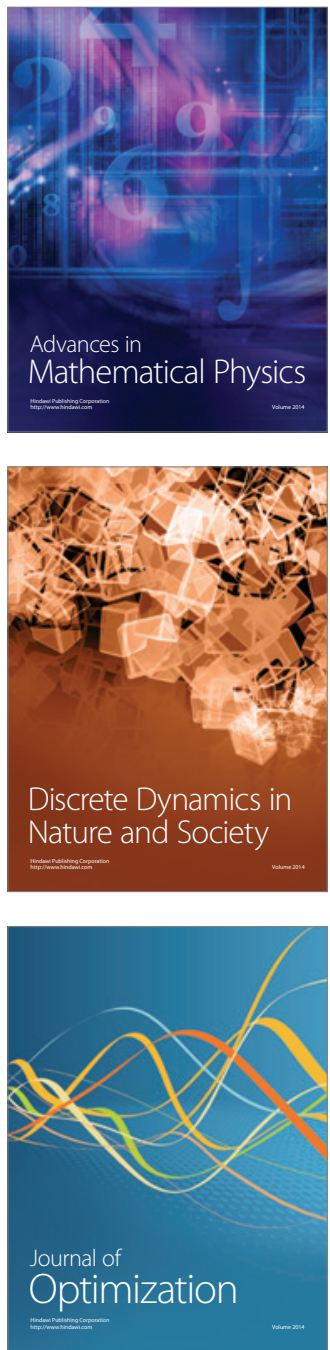